\title{
EXPERIMENTAL INVESTIGATION AND PERFORMANCE OPTIMIZATION OF A CROSS FLOW HEAT EXCHANGER BY ENTROPY GENERATION MINIMIZATION APPROACH
}

\author{
T. Mohapatra ${ }^{1}$, S. K. Rout ${ }^{1, *}$
}

\begin{abstract}
The exergy loss and performance optimization of a cross flow heat exchanger (CFHE) with air and hot water as working fluid have been experimentally investigated. Experiments are performed on various mass flow rates of hot water and air over a ranges of $0.015 \mathrm{~kg} \cdot \mathrm{s}^{-1}-0.04 \mathrm{~kg} \cdot \mathrm{s}^{-1}$ and $0.117 \mathrm{~kg} \cdot \mathrm{s}^{-1}-0.763 \mathrm{~kg} . \mathrm{s}^{-1}$ respectively. To validate the results of the present study, they are compared with available data in literature through which a reasonably a good agreement is obtained between them. This study demonstrates the successful application of Taguchi approach for optimal design of the (CFHE). The effects of design parameters and two different operating conditions such as the fin pitch, the inside tube diameter and the mass flow rate of water and air on exergy loss are investigated. In the Taguchi experimental design method, exergy loss is considered as performance parameter and it is revealed that parameter combinations such as $\dot{m}_{\mathrm{h}}=0.0163 \mathrm{~kg} \cdot \mathrm{s}^{-1}, \dot{m}_{\mathrm{a}}=0.1175 \mathrm{~kg} \cdot \mathrm{s}^{-}$ ${ }^{1}, \mathrm{~d}_{\mathrm{i}}=0.0199 \mathrm{~m}$ and $\mathrm{F}_{\mathrm{p}}=0.00259 \mathrm{~m}$ resulted optimum performance. Contribution ratios of each parameter on exergy loss are assessed. Mass flow rate of air is determined to be the most effective parameter on exergy loss with a contribution ratio of $51.26 \%$ followed by mass flow rate of hot water, fin pitch, and diameter contribution ratios of $35.91 \%, 7.02 \%, 5.79 \%$ respectively.
\end{abstract}

Keywords: Experimental Investigation, Cross Flow Heat Exchanger, Performance Optimization, Exergy Analysis, Taguchi Method

\section{INTRODUCTION}

In various industries, power plants, chemical process plants, petroleum refineries and air conditioning sectors etc. the use of cross flow heat exchangers is vast. The efficiency of the heat exchangers affects the performance of the systems significantly. Hence optimization of heat exchanger parameters and low cost have been important research topics since last two decades or more. Various approaches adopted by researchers are shape of heat exchanger, types of extended surfaces, mal distribution, Nano fluid, disturbance elements etc. to enhance the heat transfer using various methods like entropy generation principle[1], genetic algorithm[2], Taguchi method[3], exergy loss method [4] and so on. Sahin et al. [5] used the Taguchi method to conduct an experimental investigation for identifying the effects of the longitudinal fin pairs and lateral separations of consecutively on the thermos hydraulic performance. Yakut et al. [6] studied the performance of the hexagonal fins, span-wise and stream-wise distances between fins and flow velocity on heat transfer and pressure drop characteristics using Taguchi method. Kotcioglu et al. [7] experimentally analyzed the heat transfer and pressure drop in a cross-flow heat exchanger with hexagonal, square and circular pin-fin arrays. Gunes et al. [8] determined of the optimum values of the design parameters in a tube with equilateral triangular cross sectioned coiled wire inserts. Bahiraeiet al. [9] evaluated the entropy generation of a biological nanofluid containing silver nanoparticles in a liquid block heat sink for cooling of an electronic processor. They found from the analysis that irreversibility in the whole liquid block decreases with increasing either concentration or Reynolds number, which is a positive result based on second law of thermodynamics. Using CFD approach Bahiraeiet al. [10] studied the irreversibilities caused by heat transfer and friction for a power-law Nano fluid in a minichannel having chaotic perturbations were examined through calculation of entropy generation rates. Heshmatian et al [11] reported the irreversibilities caused by heat transfer and friction for the water- $\mathrm{TiO}_{2}$ nanofluid flow in a circular microchannel by evaluating entropy generation rates. Heat transfer characteristics and second law of thermodynamics are evaluated by Bahiraei et al. [12] for the water $-\mathrm{Al}_{2} \mathrm{O}_{3}$ nanofluid flow in a triangular minichannel under constant wall heat flux. The convective heat transfers and analysis of the second law of

This paper was recommended for publication in revised form by Regional Editor Sandip Kale

${ }^{1}$ Department of Mechanical Engineering, C. V. Raman College of Engineering, Bhubaneswar, Odisha, India.

*Email: sachindra106@gmail.com

Orcid id: 0000-0002-5471-1620 and 0000-0003-3016-3161

Manuscript Received 17 January 2018, Accepted 14 July 2018 
thermodynamics for the non-Newtonian nanofluid flow containing $\mathrm{TiO}_{2}$ nanoparticles within a narrow annulus was investigated by Bahiraei et al. [13].

Based upon the studies mentioned above, all of the process parameters affecting the exergy loss have not been investigated in detail. However, it has been reported that more investigations are required for cross flow of heat exchangers to optimize the design parameter based upon exergy loss. In the present investigation simultaneously both designing parameter and operating conditions are considered as process parameters for analysis using Taguchi approach where exergy loss is considered as the response parameter for designing and predicting of the CFHE.

\section{OBJECTIVE}

The objectives of the present work are

a) Validation and verification of the results of experimental approach by comparing the results of tube side convective heat transfer coefficients with the data available in the literature.

b) Performance optimization of the CFHE using entropy minimization approach.

\section{EXPERIMENTS}

\section{Experimental setup and it's description}

Experimental investigation and performance optimization of (CFHE) were carried out in the experimental set up shown in Fig. 1. The test section of the CFHE (16"x 22") is simply a fin and a tubetype cross flow heat exchanger. It consists 279 aluminum fins with a fin pitch of $2 \mathrm{~mm}$ and fin thickness of 0.3 mm. Tubes used in CFHE test sections were manufactured from "Type L" copper with inside tube diameter of $0.008525 \mathrm{~m}$ and number of tube rows was 2 . Recent study was carried out for two different fluids i.e. hot water and air. Hot water was flowing in a closed loop through the tubes of CFHE test section transferring heat into air, which was forced through the fins of the CFHE test section in an open loop by a fan working as the cooling fluid.

Hot water loop consists of a steel tank, a centrifugal pump, a flow control valve, a rotameter, two digital temperature indicator and two pressure gauges. Hot water was prepared in a steel tank of 45 liter capacity equipped with an immersion heater of $1.5 \mathrm{~kW}$ and circulated along the hot water loop by a centrifugal pump of $0.5 \mathrm{HP}$ capacity. For flow regulation and measurement of the hot water one flow control valve and the rotameter were connected after the pump. The operating range of the rotameter is $20 \mathrm{LPH}$ to $200 \mathrm{LPH}$ at a temperature is up to $90^{\circ} \mathrm{C}$. Two digital temperature indicators $\left(-50^{\circ} \mathrm{C}\right.$ to $\left.200{ }^{\circ} \mathrm{C}\right)$ and two pressure gages are connected along the hot water loop at the inlet and outlet of the CFHE test section to measure the pressures and temperatures.

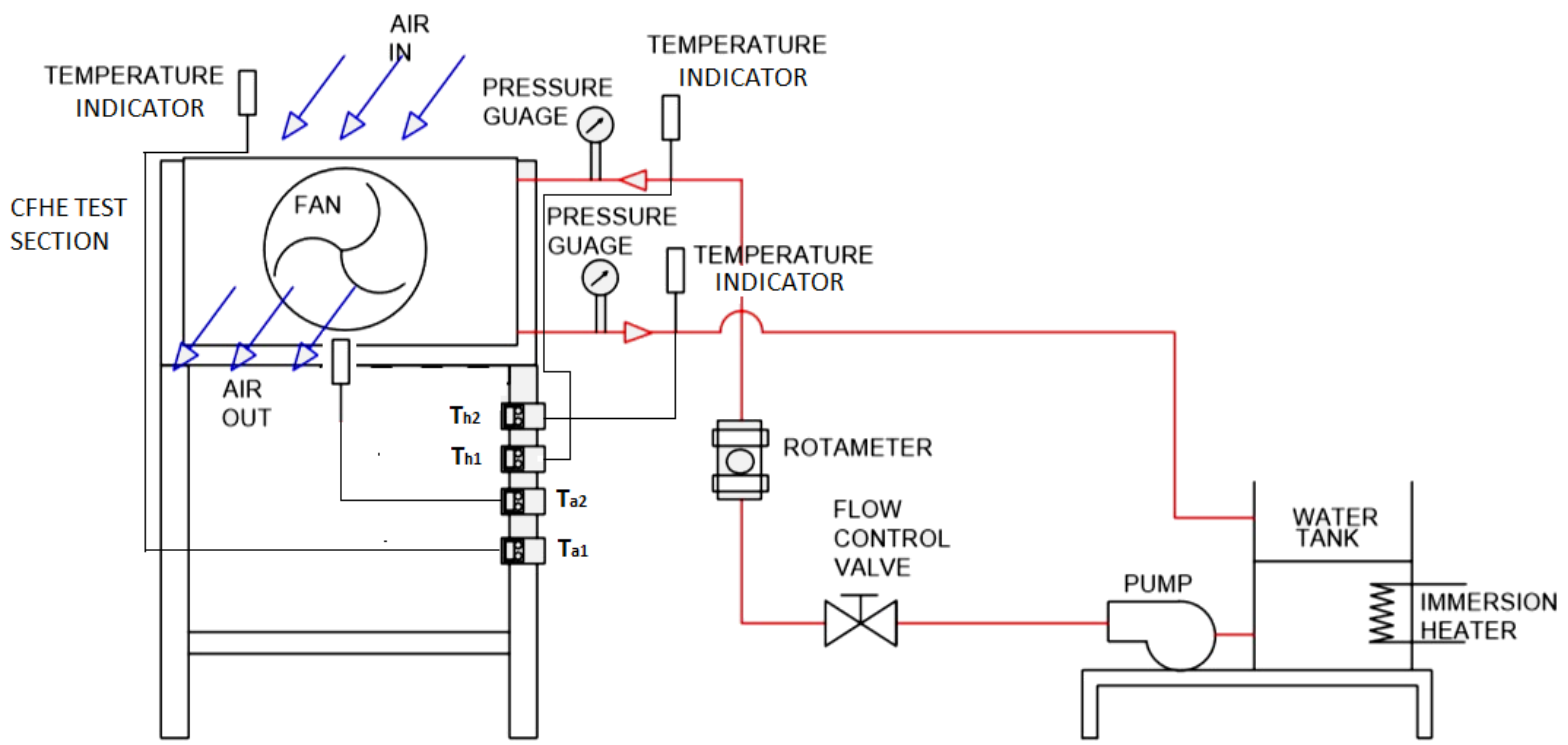

Figure 1.Schematic layout of a cross flow heat exchanger 


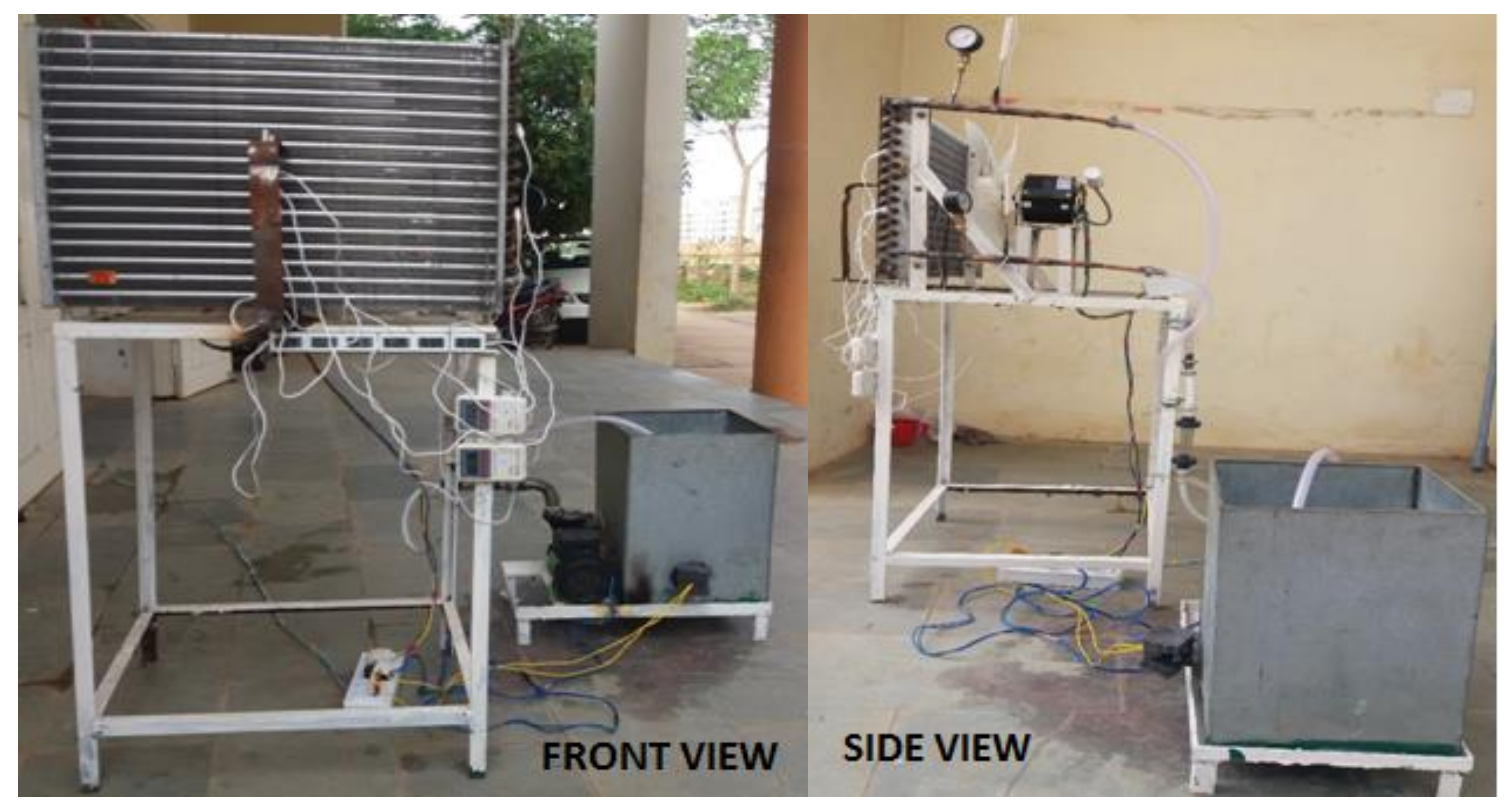

Figure 2.Experimental set up the (CFHE)

Air was forced through the CFHE test section by a fan of 14" diameter to take away the heat from the copper tubes through which hot water was flowing as shown in Fig. 2. A speed regulator was provided for the fan motor to supply air at three different speeds. Two digital temperature indicator (-50 oC to $200 \mathrm{oC})$ were connected along the open air loop to measure the temperatures of air at the inlet and outlet of the CFHE test section. An anemometer was used at the upstream i.e. in between supply fan and cross flow heat exchanger for the measurement of air velocity and at downstream air velocity decreases, when it passes over the fins and copper tubes of the CFHE.

\section{UNCERTAINTY OF MEASUREMENT}

In experimental studies, the results are typically associated with measurement errors. Uncertainty analysis is generally used to determine the experimental error and to quantify the degree of goodness of the measured values. The uncertainties in the experimental results or dependent variable $(\sigma r)$ can be expressed as a function of errors associated with different measuring instruments or independent variables ( i.e. $\sigma \times 1, \sigma \times 2, \ldots$ ,$\sigma \times n$ ) as follows:

$$
\sigma_{r}=\sqrt{\left[\left(\frac{\partial f}{\partial x_{1}}\right) \times \sigma_{x 1}\right]^{2}+\left[\left(\frac{\partial f}{\partial x_{2}}\right) \times \sigma_{x 2}\right]^{2}+\ldots+\left[\left(\frac{\partial f}{\partial x_{n}}\right) \times \sigma_{x n}\right]^{2}}
$$

A type-B uncertainty associated) with temperature measurement in digital temperature indicator is \pm 1.2 $\mathrm{oC}$, volumetric flow rate measurement in rotameter is \pm 0.324 L.min-1 and air velocity measurement in anemometer is $\pm 0.0176 \mathrm{~m}$. s${ }^{-1}$. Therefore, the uncertainty associated with the measured exergy loss is $( \pm 12.2 \%)$.

\section{CALCULATION METHOD}

\section{Data reduction}

Mass flow rate of both fluids are calculated using following formulas:

Mass flow rate of hot water:

Mass flow rate of air:

$$
\dot{m}_{h}=\rho_{h} \cdot \dot{V}_{h}
$$


Journal of Thermal Engineering, Research Article, Vol. 5, No. 2, Special Issue 9, pp. 1-12, February, 2019

$$
\dot{m}_{a}=\rho_{a} \cdot \dot{V}_{a}
$$

Heat transfer rate is calculated by

Hot water heat rejection rate:

$$
\dot{Q}_{h}=\dot{m}_{h} \cdot c_{p, h} \cdot\left(T_{h, 1}-T_{h, 2}\right)
$$

Air heat gain rate:

$$
\dot{Q}_{a}=\dot{m}_{a} \cdot c_{p, a} \cdot\left(T_{a, 2}-T_{a, 1}\right)
$$

Reynolds number are obtained from:

Hot water Reynolds number:

$$
\operatorname{Re}_{h}=\frac{\rho_{h} \cdot V_{h} \cdot d_{i}}{\mu_{h}}
$$

Air Reynolds number:

$$
\operatorname{Re}_{a}=\frac{\rho_{a} \cdot V_{a} \cdot D}{\mu_{a}}
$$

As it is observed hot water flow inside the tube is turbulent, the heat transfer coefficient, hh is calculated from Nusselt number correlation was provided by Petukhov-Popov.

$$
N u_{h}=\frac{(f / 8) \operatorname{Re}_{h} \operatorname{Pr}_{h}}{K_{1}+K_{2}(f / 8)^{1 / 2}\left(\operatorname{Pr}_{h}^{2 / 3}-1\right)} 10^{4}<\operatorname{Re}_{h}<5 \times 10^{6} 0.5<\operatorname{Pr}<2000
$$

Now heat transfer co-efficient inside the condenser tube:

$$
h_{h}=\frac{N u_{h} \cdot K_{h}}{d_{i}}
$$

Similarly the heat transfer coefficient ha can be calculated from Nusselt number correlation for flow over cylindrical tube.

$$
N u_{a}=0.027 \operatorname{Re}_{a}^{0.805} \operatorname{Pr}_{a}^{0.334}
$$

Now heat transfer co-efficient outside the condenser tube:

$$
h_{a}=\frac{N u_{a} \cdot K_{a}}{d_{o}}
$$

Overall heat transfer coefficient outside of the helical coil when heat transfer takes from hot water to air: 
Journal of Thermal Engineering, Research Article, Vol. 5, No. 2, Special Issue 9, pp. 1-12, February, 2019

$$
\frac{1}{U_{o}}=\frac{d_{o}}{h_{h} \cdot d_{i}}+\frac{A_{o} \cdot \ln \left(\frac{d_{o}}{d_{i}}\right)}{2 \pi k_{c u} L}+\frac{1}{h_{a}}
$$

\section{ENERGY BALANCE}

For the present study, we can write a steady state energy balance as follows.

From conservation of energy, it can be represented that

Heat rejected from hot water per unit time $=$ Heat gain by air per unit time + Heat loss/time

$$
\dot{Q}_{w}=\dot{Q}_{a}+\dot{Q}_{l o s s}
$$

Where,

$$
\begin{aligned}
& \dot{Q}_{w}=\dot{m}_{w} \cdot c_{p, w} \cdot\left(T_{w, 1}-T_{w, 2}\right) \\
& \dot{Q}_{a}=\dot{m}_{a} \cdot c_{p, a} \cdot\left(T_{a, 2}-T_{a, 1}\right)
\end{aligned}
$$

$\dot{Q}_{\text {loss }}=$ Heat loss/time (Which is may be radiation or any other unobserved heat loss/time)

It is observed during study that negligible heat loss/time takes place from CFHE to surrounding corresponding to increment in mass flow rates of hot water; therefore, the heat exchange process between hot water and air can be assumed to be adiabatic.

\section{EXERGY BALANCE}

Maximum useful work that is obtained reversibly in a specified environment is known as exergy. In the current study, assuming heat transfer process between hot water and air in CFHE is steady and adiabatic; overall exergy loss can be expressed as the summation of individual exergy loss related to the hot water and the air.

Considering $s=s(p, T)$, the change in specific entropy can be written as:

$$
d s=\left(\frac{\partial s}{\partial T}\right)_{p} d T+\left(\frac{\partial s}{\partial p}\right)_{T} d p
$$

Using thermodynamic relations, the change in specific entropy can also be written as:

$$
d s=\frac{c_{p}}{T} d T-\left(\frac{\partial v}{\partial T}\right)_{p} d p
$$

For a differential element the entropy variation of fluid can be given as:

$$
d S=\dot{m}\left[\frac{c_{p}}{T} d T-\left(\frac{\partial v}{\partial T}\right)_{p} d p\right]
$$

The total entropy generation in a heat exchanger is considered to be equal to the total entropy variation of both fluids. For a cross flow heat exchanger, integrating the above equation, i.e., Eq. (15), from the inlet to the outlet of air and hot water, the entropy generation rate can be written as follows: 
Journal of Thermal Engineering, Research Article, Vol. 5, No. 2, Special Issue 9, pp. 1-12, February, 2019

$$
S_{g}=\left[\int_{1}^{2} m c_{p} \frac{d T}{T}\right]_{h}+\left[\int_{1}^{2} m c_{p} \frac{d T}{T}\right]_{a}+\left[-\dot{m} \int_{1}^{2}\left(\frac{\partial v}{\partial T}\right)_{p} d p\right]_{h}+\left[-\dot{m} \int_{1}^{2}\left(\frac{\partial v}{\partial T}\right)_{p} d p\right]_{a}
$$

Rearranging Eq. (16) yields:

$$
S_{g}=S_{g, \Delta T}+S_{g, \Delta p}
$$

Where, $S_{g, \Delta T}$ is the entropy generation contributed by heat transfer and $S_{g, \Delta p}$ is the entropy generation contributed by fluid friction.

As we know, the irreversibility of fluid flow due to viscous friction is negligible as compared to that of the irreversibility of heat transfer due to finite temperature difference. Therefore the irreversibility of fluid flow is neglected in this analysis and exergy $\left[T_{o}\left(S_{g}\right)\right]$ balance performed.

$$
E=E_{h}+E_{a}
$$

Exergy losses related to the hot water flow inside the copper tubes can be written as:

$$
E_{h}=T_{o}\left\{\dot{m}_{h}(\Delta S)_{h}\right\}
$$

Where, $(\Delta S)_{h}=S_{h, 2}-S_{h, 1}=C_{p, h} \ln \left(\frac{T_{h, 2}}{T_{h, 1}}\right)$

Similarly, exergy loss related to air flow through the fins can be written as:

$$
E_{a}=T_{o}\left\{\dot{m}_{a}(\Delta S)_{a}\right\}
$$

Where, $(\Delta S)_{a}=S_{a, 2}-S_{a, 1}=C_{p, a} \ln \left(\frac{T_{a, 2}}{T_{a, 1}}\right)$

By substituting Eq. (20) in to Eq. (19) and Eq. (22) into Eq. (21), overall exergy loss can be expressed as $E=T_{o}\left\{C_{p, h} \ln \left(\frac{T_{h, 2}}{T_{h, 1}}\right)+C_{p, a} \ln \left(\frac{T_{a, 2}}{T_{a, 1}}\right)\right\}$

Dimensionless exergy loss can be determined:

$$
e=\frac{E}{T_{o} C_{\min }}
$$

Where, $C_{\min }=\operatorname{Min}\left\{\dot{m}_{h} c_{p, h}\right.$ and $\left.\dot{m}_{a} c_{p, a}\right\}$ 


\section{TAGUCHI METHOD}

Thermodynamic performance of CFHE can be enhanced considerably by using a reasonable optimization approach $[13,15]$. Numbers of factors affect the thermal performance of the CFHE and out of these factors; the principal factors are determined by Taguchi method for optimum design. As reported by Gunes et al. [13]. Taguchi method is a standardized approach for determining the best combination of input parameters to get optimum result. This is accomplished through the design of experiments (DOE). It provides a method for quantitatively identifying just the right parameters that go together for optimal performance or service. Taguchi method is associated with three design stages i.e system design, parameter design and tolerance design. In this paper, the optimum values of system parameters or thermal performance parameters i.e. $\mathrm{E}$ is determined from parameter design stage. Signal to noise ratio (SNR or $\mathrm{S} / \mathrm{N}$ ratio) measures the variations in performance parameters. $\mathrm{S}$ is the signal stands for mean and $\mathrm{N}$ is the noise stands for standard deviation in Taguchi approach. Three types of quality characteristics "larger is the better"; "nominal is the best" and "smaller is the better" are used to analyze S/N ratio. For the current study following steps of Taguchi technique are used.

Step 1 Identification of the objectives: Minimum exergy loss for the flow in the CFHE is identified as the objective of this work.

Table 1. Design factors and their levels

\begin{tabular}{|c|c|c|c|c|}
\hline Control Factors & $\mathbf{m}_{\mathbf{h}}, \mathbf{~ k g . s}^{\mathbf{1}}$ & $\mathbf{m}_{\mathbf{n}}, \mathbf{k g} . \mathbf{~ s}^{\mathbf{1}}$ & $\mathbf{d}_{\mathbf{i}}, \mathbf{m}$ & $\mathbf{F}_{\mathbf{p}}, \mathbf{m}$ \\
\hline Level 1 & 0.0163 & 0.1175 & 0.0085 & 0.0016 \\
\hline Level 2 & 0.0273 & 0.2051 & 0.0138 & 0.002 \\
\hline Level 3 & 0.0382 & 0.0138 & 0.0199 & 0.0025 \\
\hline
\end{tabular}

Step 2 Selection of characteristics: "Smaller is the better" quality characteristic is preferred for exergy loss, E. As available energy is higher at minimum exergy loss, hence "Smaller is the better" quality characteristics is preferred.Step 3 Selection of various factors and their levels: In this study, mass flow rate of hot water, mass flow rate of air, tube diameter $\left(\mathrm{d}_{\mathrm{i}}\right)$ and fin pitch $\left(\mathrm{F}_{\mathrm{p}}\right)$ are selected as the control factors for influencing exergy loss in the CFHE. The levels of control factors are represented in Table 1.

Table 2. L9 orthogonal array for control factors

\begin{tabular}{|c|c|c|c|c|}
\hline No. & $\mathbf{m}_{\mathbf{h}}^{\mathbf{h}} \mathbf{~ k g . s}^{\mathbf{1}}$ & $\mathbf{m}_{\mathbf{h}} \mathbf{~ k g . s}^{\mathbf{1}}$ & $\mathbf{d}_{\mathbf{i}, \mathbf{m}}$ & $\mathbf{F}_{\mathbf{p}, \mathbf{m}}$ \\
\hline 1 & 0.01638 & 0.1175 & 0.008525 & 1.64 \\
\hline 2 & 0.01638 & 0.2051 & 0.0138 & 2 \\
\hline 3 & 0.01638 & 0.7801 & 0.0199 & 2.59 \\
\hline 4 & 0.0273 & 0.1175 & 0.0138 & 2.59 \\
\hline 5 & 0.0273 & 0.2051 & 0.0199 & 1.64 \\
\hline 6 & 0.0273 & 0.7801 & 0.008525 & 2 \\
\hline 7 & 0.03822 & 0.1175 & 0.0199 & 2 \\
\hline 8 & 0.03822 & 0.2051 & 0.008525 & 2.59 \\
\hline 9 & 0.03822 & 0.7801 & 0.0138 & 1.64 \\
\hline
\end{tabular}

Step 4 Selection of an orthogonal array: Taguchi method is well known for design of experiments by employing a standard table known as orthogonal array for study of various design parameters relative to single quality characteristics. A suitable orthogonal array is selected depending on the number of factors with their levels, degrees of freedom, objective of the study, available resources. Minitab 16.0 is used for the analysis. For four control factors with three levels, L9 orthogonal array is generated and shown in Table 2.

Step 5 Conduction of experiments and result analysis: Orthogonal array design provides the idea about the number of experiments to be conducted in Taguchi method analysis. In this study total 9 numbers of experiments were conducted and results are presented in Table 3 for analysis. The effect of control factors on exergy loss of the CFHE are measured by SNR or S/N (signal to noise) ratio. 

2019

For exergy loss, E following formula is used during the analysis of SNR or S/N ratio for "smaller is the better" quality characteristics.

$$
S N R_{S}=-10 \log _{10}\left(E^{2}\right)
$$

The optimum levels of various design parameters are obtained according to the greatest value of S/N ratio and contribution ratios of these factors on exergy loss of the CFHE are calculated as shown in Table 4.

\section{RESULTS AND DISCUSSIONS}

\section{Validation of experimental approach}

The results of the experimental approach i.e. convective heat transfer coefficient of hot water, $h_{h}$ were compared with literature for cross flow configuration and the results are shown in Fig. 3. For verification and validation of the results of this study, the calculated convective heat transfer of hot water, $h_{h}$, were compared with the results of correlation values presented by Gnielinski [14]. There is a good agreement observed between the results of the experimental approach with the literature and thus validated.

Table 3. Mean and $\mathrm{S} / \mathrm{N}$ ratio of exergy loss, $\mathrm{E}$

\begin{tabular}{|c|c|c|c|c|c|c|c|}
\hline \multirow{2}{*}{ RUN } & \multirow{2}{*}{$\mathbf{m}_{\mathbf{h}}, \mathbf{k g . \mathbf { s } ^ { - 1 }}$} & \multirow{2}{*}{$\mathbf{m}_{\mathbf{n}}, \mathbf{k g} . \mathbf{s}^{\mathbf{- 1}}$} & \multirow{2}{*}{$\mathbf{d}, \mathbf{m}$} & \multirow{2}{*}{$\mathbf{F}_{\mathbf{p}, \mathbf{m}}$} & \multirow{2}{*}{ Exergy loss, $\boldsymbol{E}$} & \multicolumn{2}{|c|}{ Responses } \\
\cline { 7 - 8 } & & & & & & Mean & S/N Ratio \\
\hline 1 & 0.01638 & 0.1175 & 0.008525 & 1.64 & 3.451105949 & 3.451105949 & -10.75916585 \\
\hline 2 & 0.01638 & 0.2051 & 0.0138 & 2 & 4.328802392 & 4.328802392 & -12.72735522 \\
\hline 3 & 0.01638 & 0.763 & 0.0199 & 2.59 & 5.867249014 & 5.867249014 & -15.36869041 \\
\hline 4 & 0.0273 & 0.1175 & 0.0138 & 2.59 & 4.29422205 & 4.29422205 & -12.65768995 \\
\hline 5 & 0.0273 & 0.2051 & 0.0199 & 1.64 & 5.900487087 & 5.900487087 & -15.41775728 \\
\hline 6 & 0.0273 & 0.763 & 0.008525 & 2 & 9.006400795 & 9.006400795 & -19.09102539 \\
\hline 7 & 0.03822 & 0.1175 & 0.0199 & 2 & 4.928097633 & 4.928097633 & -13.85358607 \\
\hline 8 & 0.03822 & 0.2051 & 0.008525 & 2.59 & 6.832268443 & 6.832268443 & -16.69129843 \\
\hline 9 & 0.03822 & 0.763 & 0.0138 & 1.64 & 11.73446402 & 11.73446402 & -21.38926515 \\
\hline
\end{tabular}

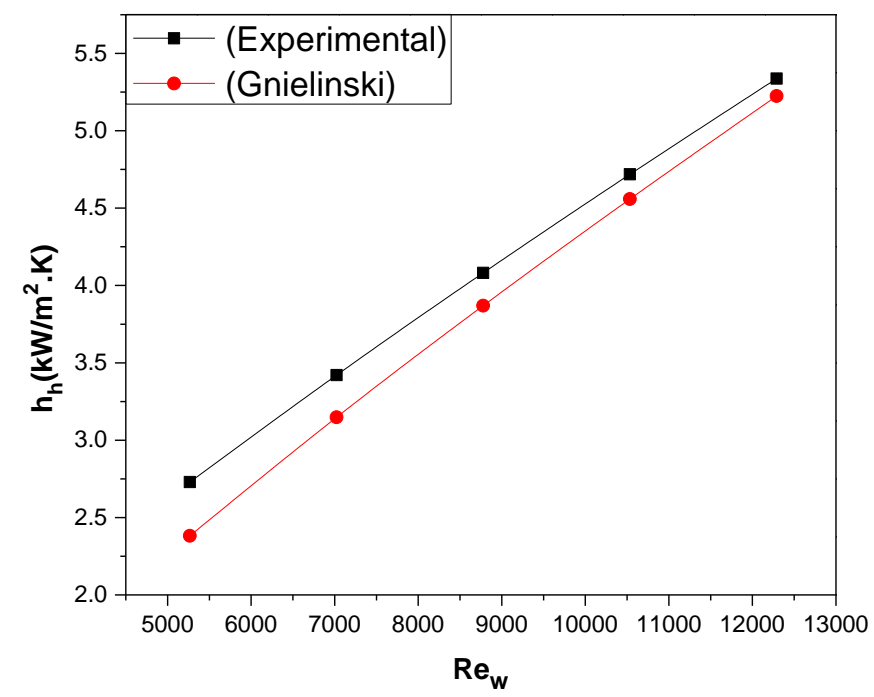

Figure 3. Validation of experimental approach 

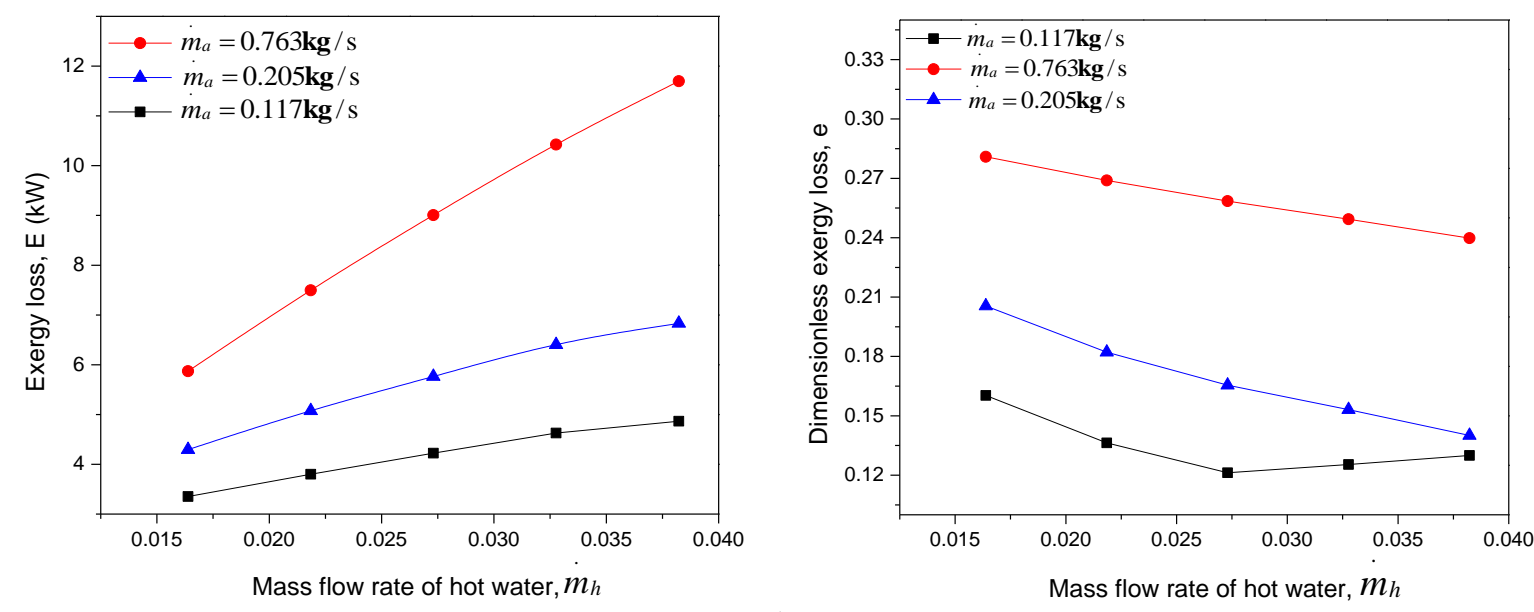

a)

b)

Figure 4. Effect of mass flow rate hot water and air on (a) exergy loss, (b) dimensionless exergy loss

Fig. 4 illustrates the effect of mass flow rate of hot water on exergy loss of the CFHE at different mass flow rates of air. The investigation is conducted at fix dimensions of heat exchanger for all cases. It is observed from Fig. 4 (a) that exergy loss increases with increment in mass flow rates of hot water and air, because more amount of hot water or air flow rate can cause more amount of Reynolds number through the cross flow heat exchanger. It is obvious that higher Reynolds number causes higher heat transfer rate. On the other hand, more heat transfer rate implies more finite temperature difference which is the reason of exergy loss.

In Fig. 4 (b), it is observed that dimensionless exergy loss decreases with the increase of hot water flow rate and increases with the increase of air flow rate. As mentioned in Eq. (23), Dimensionless exergy loss is dependent upon exergy loss and product of ambient temperature, minimum heat capacity. Therefore increment or decrement in dimensionless exergy loss is dependent upon the value of numerator and denominator of Eq. (23). It is observed during analysis that increment of denominator is dominant over increment of numerator for enhancement of hot water flow rate; whereas for enhancement of air flow rate it is reversed. Hence, enhancement of air flow rate increases the dimensionless exergy loss and the increment of hot water flow rate decreases the dimension less exergy loss.

\section{The effect of fin pitch and tube diameter on exergy loss}

Fig. 5 demonstrates the effect of fin pitch and tube diameter on exergy loss of the cross flow heat exchanger. The investigation is made at fix of other dimension of heat exchanger and air flow rate for all cases. It is observed from this figure that exergy loss and dimensionless exergy loss increases with increase in inside tube diameter, but exergy loss and dimensionless exergy loss negligibly change with increase in fin pitch.
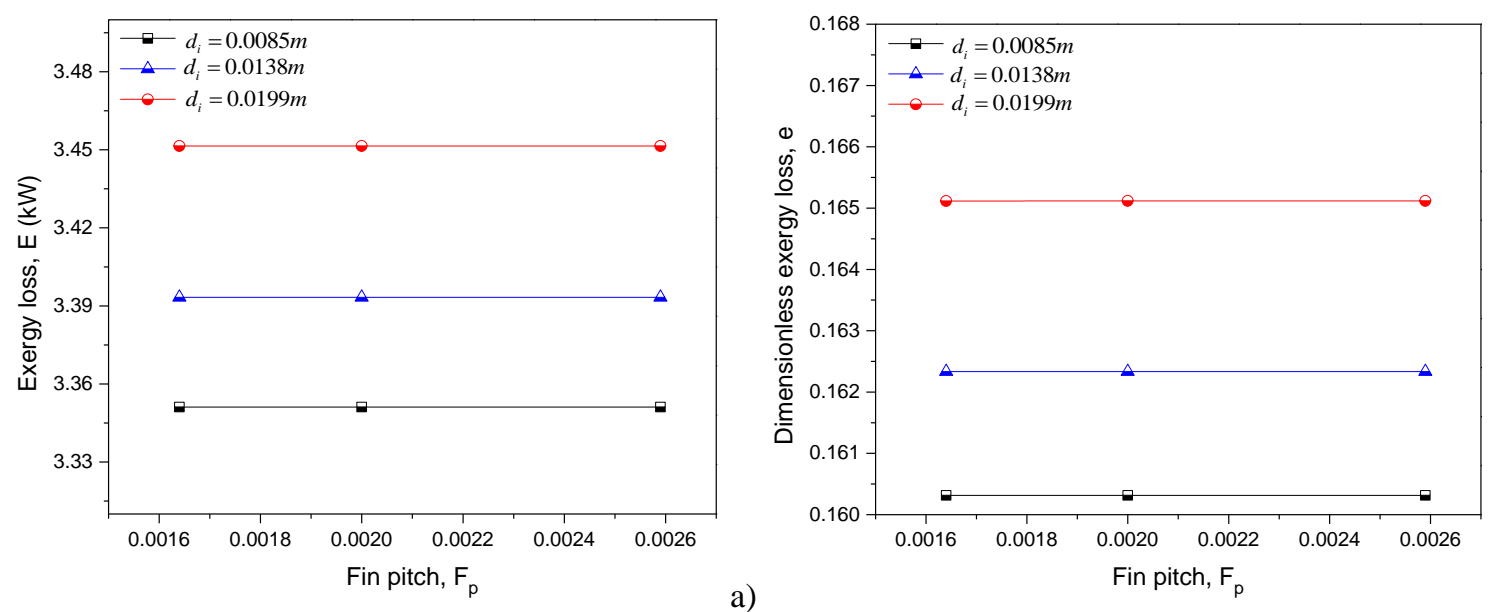

Figure 5. Effect of fin pitch and tube diameter on (a) exergy loss, (b) dimensionless exergy loss

b) 


\section{Optimum heat transfer enhancement condition}

The calculated SNR or S/N ratios for 9 numbers of experiments are shown in Table 3. The contribution of each factor on exergy loss of the CFHE is presented in Table 4, where R is the difference between the maximum and minimum $\mathrm{S} / \mathrm{N}$ ratio for each factor, contribution ratio is the ratio of $\mathrm{R}$ value of any factor to the total $\mathrm{R}$ values of all factors and rank represents the orderly assignment of factor with respect to minimum exergy loss. The optimum condition is calculated for a combination of levels of control factors having the largest $\mathrm{S} / \mathrm{N}$ ratio.
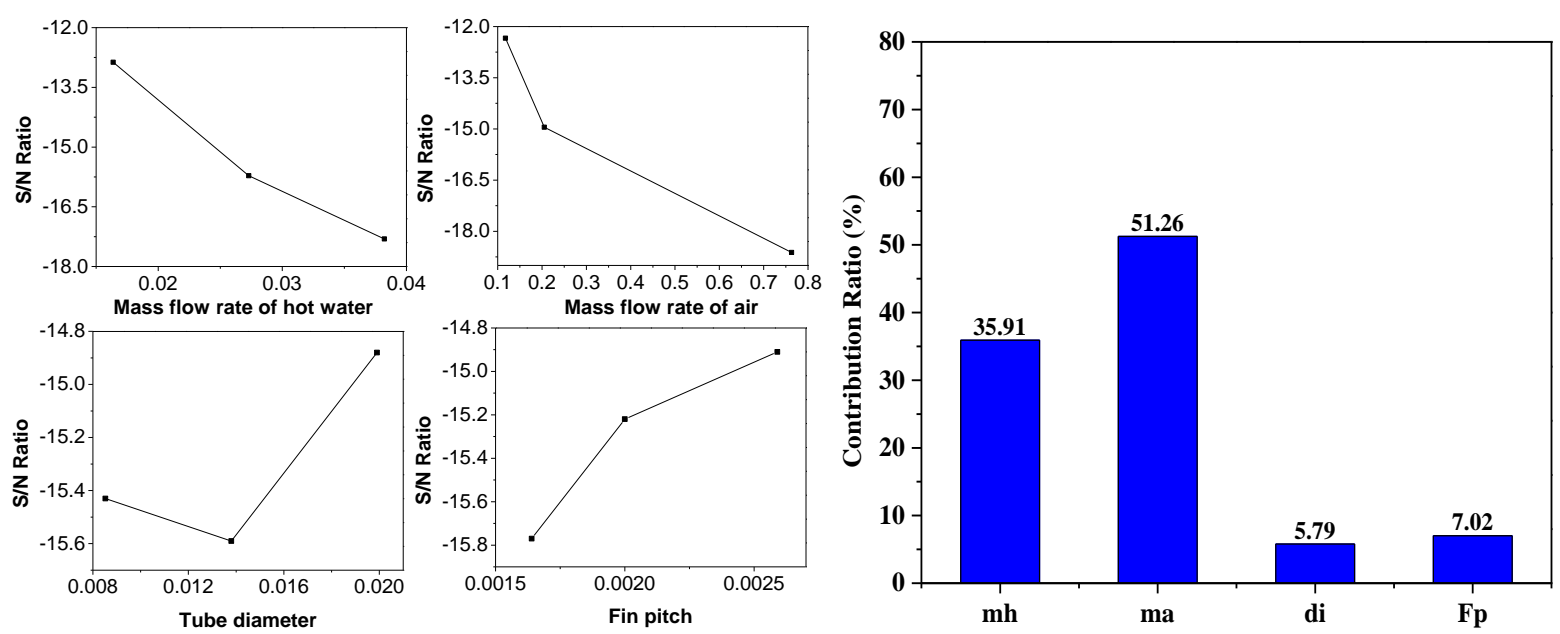

Figure 6. Effects and contribution ratio of each design parameter on exergy loss, E

The effect of each design parameters on exergy loss, E, is shown in Fig. 6. The optimum values of these design parameters for minimum exergy loss, $\mathrm{E}$, is obtained for, $\dot{\mathrm{m}}_{\mathrm{h}}=0.0163 \mathrm{~kg} \cdot \mathrm{s}^{-1}, \dot{\mathrm{m}}_{\mathrm{a}}=0.1175 \mathrm{~kg} . \mathrm{s}^{-1}, \mathrm{~d}_{\mathrm{i}}=0.0199 \mathrm{~m}$ and $\mathrm{F}_{\mathrm{p}}=0.00259 \mathrm{~m}$ according to "smaller is the better" quality characteristics. Using these optimum values another experiment is conducted and exergy loss is calculated about $3.35110719 \mathrm{~kW}$. The contribution ratio of each parameter on exergy loss is shown in Fig. 6 and Table 4. It is clear from figure that the mass flow rate of hot water is the most effective parameter on exergy loss with a contribution ratio of $51.26 \%$ followed by mass flow rate of air, fin pitch, Fp and tube diameter, di with the contribution ratio of $35.91 \%, 7.02 \%$ and $5.79 \%$ respectively. It is observed from the results that tube diameter and fin pitches have the least effect on exergy loss.

Table 4. Contribution of design parameters of the CFHE on exrgy loss, E

\begin{tabular}{|l|c|c|c|c|c|}
\hline & Level & $\dot{\mathbf{m}}_{\mathbf{h}}$ & $\dot{\mathbf{m}}_{\mathbf{a}}$ & $\boldsymbol{d}_{\boldsymbol{i}}$ & $\boldsymbol{F}_{\boldsymbol{p}}$ \\
\hline S/N Ratio & 1 & -12.87 & -12.34 & -15.43 & -15.77 \\
\hline- & 2 & -15.72 & -14.95 & -15.59 & -15.22 \\
\hline- & 3 & -17.31 & -18.62 & -14.88 & -14.91 \\
\hline $\mathrm{R}$ & - & 4.4 & 6.28 & 0.71 & 0.86 \\
\hline Rank & - & 2 & 1 & 4 & 3 \\
\hline \multicolumn{2}{l}{ Contribution Ratio \% } & 0.3591 & 0.5126 & 0.0579 & 0.0702 \\
\hline
\end{tabular}

\section{CONCLUSIONS}

In this study, experimental investigation and performance optimization of the CFHE was performed. Taguchi method was used for determination of optimum design parameters for minimum exergy loss in CFHE. The results of this work can be summarized as follows. 
1. For minimum exergy loss in CFHE, the optimum value of different design parameters were obtained as mass flow rate of hot water is $0.0163 \mathrm{~kg} / \mathrm{s}$, mass flow rate of air is $0,117 \mathrm{~kg} / \mathrm{s}$, tube diameter is $0.0199 \mathrm{~m}$ and fin pitch is $0.00259 \mathrm{~m}$.

2. Contribution ratios of each design parameter on exergy loss were determined. Mass flow rate of hot water is found out the most effective parameter on exergy loss with a contribution ratio of $51.26 \%$ followed by mass flow rate of air , fin pitch, Fp and tube diameter, di with the contribution ratio of $35.91 \%, 7.02 \%$ and $5.79 \%$ respectively.

\section{NOMENCLATURE}

\begin{tabular}{|c|c|}
\hline A & Area $\left[\mathrm{m}^{2}\right]$ \\
\hline$c_{\mathrm{p}}$ & Specific heat $[\mathrm{kJ} / \mathrm{kgK}]$ \\
\hline $\mathrm{C}$ & Heat capacity $[\mathrm{kW} / \mathrm{K}]$ \\
\hline $\mathrm{d}$ & Diameter of the tube $[\mathrm{m}]$ \\
\hline $\mathrm{E}$ & Exergy loss $[\mathrm{kW}]$ \\
\hline $\mathrm{F}_{\mathrm{p}}$ & Fins pitch $[\mathrm{m}]$ \\
\hline $\mathrm{h}$ & Convective heat transfer coefficient $\left[\mathrm{kW} / \mathrm{m}^{2} \mathrm{~K}\right]$ \\
\hline $\mathrm{K}$ & Thermal conductivity $[\mathrm{kW} / \mathrm{mK}]$ \\
\hline $\mathrm{L}$ & Length of the copper tube $[\mathrm{m}]$ \\
\hline$\dot{\mathrm{m}}$ & Mass flow rate $[\mathrm{kg} / \mathrm{s}]$ \\
\hline $\mathrm{Nu}$ & Nusselt number \\
\hline $\mathrm{p}$ & Pressure $[\mathrm{kPa}]$ \\
\hline $\operatorname{Pr}$ & Prandtl number \\
\hline$Q$ & Rate of heat transfer $[\mathrm{kW}]$ \\
\hline $\mathrm{Re}$ & Reynolds number \\
\hline $\mathrm{S}$ & Entropy $[\mathrm{kJ} / \mathrm{K}]$ \\
\hline $\mathrm{s}$ & Specific entropy $[\mathrm{kJ} / \mathrm{kgK}]$ \\
\hline SNR & Signal to noise ratio \\
\hline $\mathrm{T}$ & Temperature, $\mathrm{K}$ \\
\hline $\mathrm{U}$ & Overall heat transfer coefficient $\left[\mathrm{Kw} / \mathrm{m}^{2} \mathrm{~K}\right]$ \\
\hline $\mathrm{V}$ & Velocity $[\mathrm{m} / \mathrm{s}]$ \\
\hline V & Volumetric flow rate $\left[\mathrm{m}^{3} / \mathrm{sec}\right]$ \\
\hline$\rho$ & Density $\left[\mathrm{kg} / \mathrm{m}^{3}\right]$ \\
\hline$v$ & Kinematic viscosity $\left[\mathrm{m}^{2} / \mathrm{s}\right]$ \\
\hline$\mu$ & Dynamic Viscosity $\left[\mathrm{Ns} / \mathrm{m}^{2}\right]$ \\
\hline 1 & Inlet \\
\hline 2 & Outlet \\
\hline $\mathrm{a}$ & air \\
\hline $\mathrm{Cu}$ & Copper \\
\hline $\mathrm{h}$ & Hot water \\
\hline I & Inner \\
\hline Min & Minimum \\
\hline o & Outer \\
\hline $\mathrm{S}$ & Smaller \\
\hline $\mathrm{w}$ & Water \\
\hline
\end{tabular}

\section{REFERENCES}

[1] Ko, T.H. (2006). Thermodynamic analysis of optimal curvature ratio for fully developed laminar forced convection in a helical coiled tube with uniform heat flux. International Journal of Thermal Sciences, 45(7), 729737.

[2] Imran, M., Pambudi, N.A., Farooq, M. (2017).Thermal and hydraulic optimization of plate heat exchanger using multi objective genetic algorithm. Case Studies in Thermal Engineering, 10, 570-578. 
[3] Kotcioglu, I., Cansiz, A., Nasiri Khalaji, M. (2013). Experimental investigation for optimization of design parameters in a rectangular duct with plate-fins heat exchanger by Taguchi method. Applied Thermal Engineering, 50, 604-613.

[4] Ipek, O., Kılic, B., Gurel, B. (2017). Experimental investigation of exergy loss analysis in newly designed compact heat exchangers. Energy, 124, 330-335.

[5] Sahin, B. (2005). Optimum design parameters of a heat exchanger. Applied Energy, 82(1), 90-106.

[6] Yakut, K. (2006). Experimental investigation of thermal resistance of a heat sink with hexagonal fins. Applied Thermal Engineering, 26(17), 2262-2271.

[7] Kotcioglu, I., Caliskan, S., Baskaya S. (2011). Experimental study on the heat transfer and pressure drop of a cross-flow heat exchanger with different pin-fin arrays. Heat and mass transfer, 47(9), 1133.

[8] Bahiraei, M., Heshmatian, S. (2017). Application of a novel biological nanofluid in a liquid block heat sink for cooling of an electronic processor: Thermal performance and irreversibility considerations. Energy Conversion and Management, 149, 155-167.

[9] Bahiraei, M., Gharagozloo, K., Alighardashi, M, Mazaheri, N. (2017). CFD simulation of irreversibilities for laminar flow of a power-law nanofluid within a minichannel with chaotic perturbations: An innovative energyefficient approach. Energy Conversion and Management, 144, 374-387.

[10] Heshmatian, S., Bahiraei, M. (2017). Numerical investigation of entropy generation to predict irreversibilities in nanofluid flow within a microchannel: Effects of Brownian diffusion, shear rate and viscosity gradient. Chemical Engineering Science, 172, 52-65.

[11] Bahiraei, M., Mohammadi, S. (2016). Prediction of entropy generation for nanofluid flow through a triangular minichannel using neural network. Advanced Powder Technology, 27, 673-683.

[12] Bahiraei, M., Alighardashi, M. (2016). Investigating non-Newtonian nanofluid flow in a narrow annulus based on second law of thermodynamics. Journal of Molecular Liquids, 219, 117-127.

[13] Gunes, S., Manay, E., Senyigit, E., Ozceyhan, V. (2011). A Taguchi approach for optimization of design parameters in a tube with coiled wire inserts. Applied Thermal Engineering, 31, 2568-2577.

[14] Gnielinski, V. (1976). New equation for heat and mass transfer in turbulent pipe and channel flow, International Chemical Engineering, 16, 359-368.

[15]Rout S.K., Choudhury B. K, Sahoo R. K., Sarangi S. K. (2014). Multi-objective parametric optimization of Inertance type pulse tube refrigerator using response surface methodology and non-dominated sorting genetic algorithm.Cryogenics 62, 71-83. 